\title{
ТВОРЧЕСКИЙ ПРОЦЕСС: ХУДОЖНИК И ХУДОЖЕСТВЕННЫЙ МАТЕРИАЛ В ИХ ИСКУСНОСТИ, ИСКУССТВЕННОСТИ И ИСКУСЕ
}

Аннотация. В статье рассматривается творческий процесс как диалог художника с художе-
ственным материалом, когда, выступая в единстве «искусственности», «искусности» и «искса»,
художник способен про-изводить из небытия в присутствие произведения искусства. Анализируются
качественные характеристики мастерства создателя художественных произведений. Утверж-
дается, что отношение худонника и художественного материала представляет собой игровое
взаимодействие, необходмое для появления произведений искусства. Ключевъе слова: Философия, творческий процесс, художни, художественный материал, искусность, искусственность, искус, произведение искусства, мастерство, диалог.

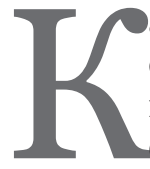
аждый человек обладает в той или иной степени сформированным синтетическим мышлением, однако лишь художники в среде создателей продуктов «второй природы» являются носителями воистину развитого визуального мышления, посредством которого во взаимодействии с художественным материалом они, выступая в единстве «искусственности», «искусности» и «искуса», способны про-изводить из небытия в присутствие произведения искусства ${ }^{1}$.

Производство художественных произведений принято представлять как творческий процесс, длящийся от акта возникновения художественной идеи в голове автора до факта освоения произведения реципиентом в виде продукта. В подобном процессе вычленяют ряд этапов: а) зарождение замысла (идеи) грядущего произведения; б) материальное воплощение данного замысла; в) функционирование произведения-вещи в качестве предмета (продукта) художественного восприятия.

Творческий диалог художника с материалом искусства предстает здесь как изготовление некоего чувственно доступного передатчика художественной информации, польза от которого возрастает по мере корректности донесения замысла от творца искусства до зрителя.

\footnotetext{
1 Жуковский В.И., Пивоваров Д.В. Природа визуального мышления // Журнал Сибирского федерального университета. Гуманитарные науки. 2008. № 1(1). С. 149-158.
}

«Искусность» художника - это качественная характеристика квалификации, умелости, мастерства создателя произведений искусства. «Искусственность» художника в этом случае понимается как некая особенная духовно-материальная деятельность в границах определенной профессиональной сферы, которая извне подобных границ предстает в качестве чего-то «экстраординарного», «исключительного», «феноменального», «неестественного». «Искус» же художника есть тот соблазн, что удерживает на протяжении жизни производителя художественных творений в границах его профессии ${ }^{2}$.

«Искусность» художника позволяет себя понять через обращение к древнегреческому «техне», ибо у эллинов данное слово означало именно умение, высокое мастерство, способность в какой-либо области производства. Кстати, сплошь и рядом понятие «искусность» принято отождествлять с понятием «искусство» вообще. Например, В.И. Даль определяет «искусство» в качестве принадлежности искусного: «искусность, умение, развитая навыком или учением способность, мастерство ${ }^{3}$. М. Фасмер в своем этимологическом словаре фиксирует: «Искусство - это проба, опыт, практика, основанное

\footnotetext{
2 Жуковский В.И. Теория изобразительного искусства: [монография]. СПб: Алетейя, 2011. С. 112-113.

3 Даль В.И. Толковый словарь живого великорусского языка: В 4 т. М., 1978. Т. 2. С. 52.
} 


\section{Философия и искусство}

на опытах доказательство » 4 . В энциклопедическом словаре В.Г. Власова дается следующая трактовка: «Искусство - опытное знание, навыки и умения;

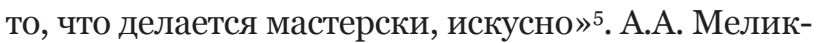
Пашаев в «Современном словаре-справочнике по искусству» толкует: «Искусство есть отточенное мастерство, «искушенность» в каком бы то ни было отношении» ${ }^{6}$.

Овладение «техне» как «искусностью» означало в древности проникновение в тайники божественного творящего умения. Природа творит, выпуская вещь из несуществования в наличное бытие, и художник, моделируя божественные принципы, творит, про-изводя вещь из потаенности в открытость. Можно сказать, что «искусность» как «техне» есть повод-причина про-изведения вещи в ее художественном качестве.

В «первой» природе процесс про-изведения по направлению к вещному результату, форме и конфигурации («эйдос») происходит под действием созидающего начала (Бог, Дух, Природа, Абсолют).

Во «второй» природе процесс про-изведения по направлению к вещественному результату происходит по причине «искусности» художнического визуального мышления и его разумной воли, но под эгидой божественных законов и цели.

Где есть «техне», там есть «мехос» (механизм, машина, махина, махинация), означая у греков нечто подобное уловке или средству помощи в сложной ситуации. Производная конструкция от «мехос» - «механе» также имела первоначальное значение лекарства, ухищрения или умно придуманного инструментального средства, с помощью которого позволительно добыть, получить, произвести нечто такое, что жизненно необходимо.

Нужда в «искусности» (как «техне» и «мехос») возникает в случае каких-либо нарушений в протекании жизненной естественности. Ведь непосредственная человеческая деятельность, подобная дыханию, движению, принятию пищи, сну и пр., не называется «искусностью» как «техне». Лишь тогда, когда в этой деятельности случаются сбои, грозящие нарушению естественного хода жизни в единстве ее самоутверждения и соучастия, возникает потребность в разумно-волевых

\footnotetext{
4 Фасмер М. Этимологический словарь русского языка: в 2 т. M., 1986. T. 2. C. 141.

5 Власов В.Г. Большой энциклопедический словарь изобразительного искусства: в 8 т. СПб, 2000. Т. 3. С. 350-354.

${ }^{6}$ Мелик-Пашаев А.А. Современный словарь-справочник по искусству. М., 1999. С. 258-261.
}

преднамеренных инструментальных действиях, характеризующихся мастерством, умелостью и хитростью («искусность»), дабы восстановить нарушенное или утраченное. Тогда начинают говорить о «техне» дыхания, сна, ходьбы, еды и пр. Получается, что необходимость в «искусной» инструментальной «второприродной» махинации вызвана желанием восстановить «искусственно», воссоздать из-за чего-то нарушенные некие «первоприродные» смысложизненные процессы, возрождая их «естественность».

«Искусность» художника можно представить в виде нескольких квалификационных ярусов:

- «искусность» в качестве минимального уровня умения, компетентности, профессиональной подготовленности;

- «суперискусность» как уровень виртуозного владения мастерством создания художественных творений;

- «метаискусность» в качестве уровня поствиртуозности с преодолением супермастерства, теряющего здесь значимость и самоценность.

«Искусность» как ярус «техне»- это та планка художнических ориентаций в сфере умений, правил, выучки, ниже которой о творении ценностей искусства не может быть и речи. Об обретении квалификационной метки «искусности» в средневековых ремесленных цехах, например, свидетельствовало образцовое изделие, которое должен был исполнить и представить на суд компетентного жюри художник для получения звания «мастер».

«Суперискусность» (лат. super - «сверху», «над») как ярус «техне» - это показатель наивысшего технического умения в области про-изводства произведений искусства. Вместе с тем «суперискусность» - это холодность, манерность, кокетство, бравада превосходством, жажда первенства. Подобный уровень «искусности» связан с изощренным владением прежде освоенными навыками, виртуозной обработкой чего-то уже полученного, поэтому вектором своим «суперискусность» обращена к сложившемуся в прошлом и ориентирована преимущественно на самоутверждение художника через манерность формальных и содержательных сторон его произведений.

«Метаискусность» (гр. meta - «после», «за», «через») как ярус «техне» - это показатель качества «искусности», обнаруживающий своего рода иронизацию художника над собственной виртуозностью. По отношению к суперискусным действиям, основанным на правилах традиционых 


\section{Философия и культура 4(64) • 2013}

навыков, здесь наблюдается некоторое дистанцирование от освоенных прежде норм как свидетельство того, что этап обычного ремесленного порождения художественных вещей прошел. Именно в области «метаискусности» случается собственно «искусность» как моделирование «первоприродных» принципов творчества при создании произведений «второприродных».

«Искусный» художник творит в ложе рутинных художественных правил стиля, метода, направления, школы,

«Суперискусный» художник - это мастер, постоянно лидирующий в стиле, методе, направлении, школе с хроническим стремлением доказать всем окружающим и самому себе, что он лучший в данной профессии.

«Метаискусный» художник есть творческий гений. Иммануил Кант, специально занимавшийся проблемой человеческой гениальности, в «Критике способности суждения» отметил: «Посредством гения природа предписывает правила искусству... Гений есть талант (дар природы) создавать то, для чего не может быть дано определенное правило, а не умение создавать то, чему можно научиться, следуя определенному правилу... Продукты гения являются образцом, то есть служат примером, руководством или правилом суждения»7.

«Искус» художника может быть определен как «желание», «потребность», «хотение», «стремление», «воление», «нужда», «соблазн» мастера в качестве «искусника» творить произведения искусства. Причем цель подобного творения предстает:

- во-первых, как «самоутверждение»,

- во-вторых, как единство личного «самоутверждения и соучастия в самоутверждении социума»,

- в-третьих, как единство личного «самоутверждения и соучастия в самоутверждении Полноты Бытия».

Про-изводство произведений искусства - это всегда авторское усилие, личностное самоутверждение. Но при этом «личность» может предстать:

- как «личинность», то есть эгоцентрированность художника на собственной персоне и ее первенствующем положении во вселенной,

- как «антилишность», то есть «нужность» художника-героя некому социальному организму,

- как «ликность», то есть как Совершенное, проявленное через совершенство конкретного лика, избранного художника-пророка.

\footnotetext{
7 Кант И. Критика способности суждения. М., 1994. С. 180, 181.
}

«Искус» самоутверждения художника имеет ряд аспектов:

- прославиться, стать знаменитым;

- разбогатеть;

- попасть в сферу избранных, войти в слой элиты;

- максимально самовыразиться, проявить свои творческие потенции;

- художественно познать окружающий мир;

- продлить свою жизнь после смерти (память потомков, вещи-произведения из «вечных» материалов и пр.);

- извести, извлечь из небытия в бытие произведения искусства в качестве вещей «второй» природы и получить от результата «дозу адреналина»;

- получить «дозу адреналина» от процесса производства произведений.

- д достичь предельного мастерства в профессии;

- открыть художественно новое, оставив «след» в искусстве (так называемый «синдром Колумба»).

«Искус» самоутверждения и соучастия художника в самоутверждении социума имеет следующие аспекты:

- прославить своей художественной деятельностью кого-либо или что-либо (семью, род, религию, страну, нацию, профессию, время и пр.);

- быть художником-идеологом, проявить себя в качестве «социализатора» людских масс;

- быть художником - эстетическим воспитателем народа;

- быть художником - этическим воспитателем социума;

- быть художником - выразителем доктрин определенной религиозной конфессии.

«Искус» самоутверждения и соучастия $x y$ -

дожника в самоутверждении Полноты Бытия означает:

- осуществить художественными средствами «метаискусную» коммуникацию между конечным и бесконечным посредством репрезентанта произведения искусства.

«Искусственность» художника может быть раскрыта следующим образом:

- стремлением мастера индивидуально эволюционировать в профессии «художник» и преодолеть собственными усилиями состояние профанной равности с прочими людьми в их конечности; «искусственность» художника предстает в качестве инициативной службы самому себе, своему саморазвитию. 


\section{Философия и искусство}

- проявлением через мастера как элемента или органа человеческого сообщества определенной «художнической» функции, необходимой для жизнедеятельности социального организма.

«Искусственность» художника предстает в качестве героической службы социуму. Герберт Спенсер, например, в работе «Социальный организм», наследуя Платону, Гоббсу и др., подробно изложил пункты сходства социального и индивидуального организмов:

1. «Начинаясь соединением небольшого числа частей, индивидуальный и социальный организмы нечувствительно увеличиваются в объеме до такой степени, что некоторые из них, наконец, достигают размера, в десять тысяч раз большего, нежели их первоначальный размер.

2. Имея вначале до того простое строение, что массу их можно бы считать совершенно бесстройной, индивидуальный и социальный организмы принимают по мере возрастания своего все более и более сложное строение.

3. Хотя в первоначальном неразвитом состоянии индивидуального и социального организмов почти не существует взаимной зависимости их частей, части эти постепенно приобретают взаимную зависимость, которая, наконец, делается так велика, что жизнь и деятельность каждой части обусловливаются жизнью и деятельностью прочих частей.

4. Жизнь и развитие социального и индивидуального организмов независимы от жизни и развития какой-либо из составляющих их единиц и гораздо продолжительнее существования этих единиц, так как они рождаются, развиваются, действуют, воспроизводятся и умирают каждая сама по себе, между тем как социальный и индивидуальный организмы, состоящие каждый из подобных единиц, переживают это, увеличиваясь в массе своей, совершенствуясь в своем строении и в деятельности своих отправлений. Ни в каком сложном теле, кроме органического и социального, нет этого беспрерывного выбывания и замены частей при продолжающейся ненарушимости целого.

5. Хотя социум не имеет специфических для индивидуального организма внешних форм, следует помнить, что во всем растительном царстве, равно как и в низших отделах животного царства, формы часто бывают весьма неопределенны, составляя скорее правило, нежели исключение.
6. Хотя живые элементы индивидуального организма по большей части безотлучно остаются каждый на своем месте, а элементы социального организма одарены способностью передвигаться с места на место, различия и тут мало, потому что если граждане как личности, имеют способность перемещения, то как части общества они неподвижны.

7. Хотя в индивидуальном организме только известный род ткани одарен чувствительностью, а в социальном организме все члены одарены ею, это различие далеко небезусловно. В некоторых из низших животных организмах, отличающихся отсутствием нервной системы, та несовершенная чувствительность, которой они обладают, одинаково распространяется на все части. При этом следует помнить, что и общественный организм не лишен некоторой дифференциации чувствительности. Единицы общества хотя и все чувствительны, но чувствительны не в равной степени» ${ }^{8}$.

«Искусственность» художника предстает в качестве пророческой службы Абсолюту. Реализация дара посредством художественной деятельности как откровения свыше, божественной избранности. В Ветхом Завете, например, есть место, где описывается сцена назначения лично Господом мастера, который должен художественно сотворить Скинию Завета: «И сказал Господь Моисею, говоря: Смотри, Я назначаю именно Веселиила, сына Уриева, сына Орова, из колена Иудина. И Я исполнил его Духом Божиим, мудростию, разумением, ведением и всяким искусством, работать из золота, серебра и меди, резать камни для вставливания и резать дерево для всякого дела. И вот, Я даю ему помощником Аголиава, сына Ахисамахова, из колена Данова, и в сердце всякого мудрого вложу мудрость, дабы они сделали все, что Я повелел тебе» (Исх. 31: 2-11).

«Искусственность» может быть духовно-материальной деятельностью преимущественно «одномерного» художника, живущего «во плоти» и творящего «по плоти».

«Искусственность» может предстать в качестве духовно-материальной деятельности преимущественно «двухмерного» художника, живущего как тело (целое) души и плоти и творящего «душевноплотские» произведения.

«Искусственность» может являться духовноматериальной деятельностью всецело «трехмер-

\footnotetext{
8 Спенсер Г. Опыты научные, политические и философские. Минск, 1998. С. 272-276.
} 


\section{Философия и культура 4(64) • 2013}

ного» художника, способного в своих творениях моделировать единство плоти, души и Духа.

Художник в его «искусственности» является производителем вещей «второй» природы не функциональных с точки зрения бытовой необходимости. Художник в его «искусственности»носитель специализированных «искусности» и «искуса».

- «Искусственность» художника - это деятельность художника как интегрального интроверта, то есть человека, всю жизнь располагающего свои смысложизненные интересы в сфере собственной «внутренней жизни» («страдательность» художника).

- «Искусственность» художника - это деятельность художника как интегрального экстраверта, то есть человека, всю жизнь располагающего свои смысложизненные интересы в сфере экспансии себя вовне в качестве субъекта с неизбежным при этом потеснении других художников в пространстве искусства («пансубъектность» художника).

- «Искусственность» - это деятельность художника как локального интроверта, то есть человека, лишь на определенных фазах своей творческой биографии погружающегося в сферу собственной «внутренней жизни».

- «Искусственность» - это деятельность художника как локального экстраверта, то есть человека, лишь на определенных фазах своей творческой биографии проявляющего свойства художественной «пансубъектности».

- «Искусственность» художника - это деятельность художника как интегрального интроверта и локального экстраверта, то есть человека, который на протяжении всей жизни творчески проявляется в своей «страдательности», иногда выказывая при этом качество «пансубъектности».

- «Искусственность» художника - это деятельность художника как интегрального экстраверта и локального интроверта, то есть деятеля искусства, который на протяжении собственной творческой биографии выступает как «пансубъект», эпизодами выказывая «страдательность».

- «Искусственность» художника - это деятельность художника как интегрального интроверто-экстраверта, то есть мастера искусства, что всю жизнь одновременно проявляется и в своей «страдательной» самопогруженности, и в своей индивидуальной «пансубъектности».
- «Искусственность» художника - это деятельность художника как локального интровертоэкстраверта, то есть творца художественных ценностей, вся творческая биография которого насыщена эпизодическими «качельными» заявлениями о себе и в качестве «страдательного» существа, и в качестве существа «пансубъектного».

- «Искусственность» художника - это обостренное желание «смерти» как растворения конечного в бесконечном, «искусственность» неустанной жажды производить все новые и новые произведения искусства в качестве иллюзорно-конечных вещей «второй» природы. Художник производит произведения искусства не один, а во взаимодействии с тем, что корректно можно назвать «художественным материалом». Но что есть «художественный материал» и как он проявляется в своих «искусственности», «искусности» и «искусе»?

Художественный материал - это вещество, потенциально в существующем мире отвечающее качеству сущности бескачественного, бесконечного Абсолюта. Именно в этом диалектика его «искусственности» (быть одновременно всем и ничем), «искусности» (мастерство стать всем из ничего) и «искуса» (соблазн произвести все из ничего).

Архетипом художественного материала является глина, взаимодействующая с художником при производстве произведений искусства еще в эпоху палеолита. Глина же, наряду с огнем, воздухом и водой, также применяемых с древности при создании произведений, есть стихии, то есть не что иное, как кирпичики-элементы, из которых сложено, сконструировано мироздание. Материал стихий избирает сам Творец для процесса производства «первой» природы как мира «естественного». И этот же материал предлагается художнику и выбирается им для творческого соития в процессе производства произведений «второй» природы как мира «искусственного».

Каждый художественный материал ограничен по своим техническим характеристикам, но, с другой стороны, неограничен, поскольку проявить свойства материала можно всегда до известного уровня, лишь частично освоив его бесконечные возможности.

Художественный материал в «узком» смысле слова - это глина, металл, камень, дерево, холст, краски, бумага, графит и пр.

Художественный материал в «широком» смысле слова может выступить спектром тем и 


\section{Философия и искусство}

сюжетов - от общих религиозно-мифологических до единичных обыденных, поскольку всеобщее как субстанциальное свойство присуще всякому явлению.

Для зарождения и развития любого творения искусства необходимы два «родителя». Если «отцом» произведения является «художник», то его «мать» - это художественный материал, представленный в форме таких особенных вещей окружающего мира, которые обладают потенцией союза единичного и всеобщего.
Художник и художественный материал не могут друг без друга, их отношение между собой представляет собой игровое взаимодействие, необходимое для появления из небытия в существование произведения искусства в его вещественности, то есть в качестве габаритного предмета, доступного органам чувств. Овеществленное произведение, будучи плодом отношения художника и художественного материала, в запечатленном виде представляет собой интеграл свойств конечного и бесконечного полюсов этого взаимодействия.

\section{Список литературы:}

1. Власов В.Г. Большой энциклопедический словарь изобразительного искусства: в 8 т. СПб: ЛИТА, 2000. T. 3. 847 c.

2. Даль В.И. Толковый словарь живого великорусского языка: в 4 т. М., 1978. Т. 2. 779 с.

3. Жуковский В.И., Пивоваров Д.В. Природа визуального мышления // Журнал Сибирского федерального университета. Гуманитарные науки. 2008. № 1 (1). С. 149-158.

4. Жуковский В.И. Теория изобразительного искусства: [монография]. СПб: Алетейя, 2011. 496 с.: ил.

5. Кант И. Критика способности суждения. М.: Искусство, 1994. 365 с.

6. Современный словарь-справочник по искусству / Науч. ред. и сост. А.А. Мелик-Пашаев. М.: Олимп: ACT, 1999. 813 c.

7. Пивоваров Д.В. Проблема синтеза главных определений культуры // Журнал Сибирского федерального университета. Серия «Гуманитарные науки». 2009. Т. 2. № 1. С. 17-22.

8. Спенсер Г. Опыты научные, политические и философские. Минск: Современный литератор, 1998. $1407 \mathrm{c}$.

9. Фасмер М. Этимологический словарь русского языка: в 4 т. М.: Прогресс, 1986. Т. 2. 672 с.

10. Zhukovskiy V.I., Pivovarov D.W. Works of art and visual thinking // European journal of natural history. 2010. № 2. P. 38-42.

11. Zhukovskiy V.I., Pivovarov V.D. Characteristics of visual thinking The // European journal of natural history. 2009. № 6. P. 38-44.

\section{References (transliteration):}

1. Vlasov V.G. Bol'shoy entsiklopedicheskiy slovar' izobrazitel'nogo iskusstva: V 8 t. SPb: LITA, 2000. T. 3. 847 c.

2. Dal' V.I. Tolkovyy slovar' zhivogo velikorusskogo yazyka: V 4 t. M., 1978. T. 2. 779 s.

3. Zhukovskiy V.I., Pivovarov D.V. Priroda vizual'nogo myshleniya // Zhurnal Sibirskogo federal'nogo universiteta. Seriya «Gumanitarnye nauki». 2008. № 1 (1). S. 149-158.

4. Zhukovskiy V.I. Teoriya izobrazitel'nogo iskusstva: [monografiya]. SPb: Aleteyya, 2011. 496 s.: il.

5. Kant I. Kritika sposobnosti suzhdeniya. M.: Iskusstvo, 1994. 365 s.

6. Sovremennyy slovar'-spravochnik po iskusstvu / Nauch. red. i sost. A.A. Melik-Pashaev. M.: Olimp: AST, 1999. $813 \mathrm{~s}$.

7. Pivovarov D.V. Problema sinteza glavnykh opredeleniy kul'tury // Zhurnal Sibirskogo federal'nogo universiteta. Seriya «Gumanitarnye nauki». 2009. T. 2. № 1. S. 17-22.

8. Spenser G. Opyty nauchnye, politicheskie i filosofskie. Minsk: Sovremennyy literator, 1998. 407 s.

9. Fasmer M. Etimologicheskiy slovar' russkogo yazyka: V 4 t. M.: Progress, 1986. T. 2. 672 s.

10. Zhukovskiy V.I., Pivovarov D.W. Works of art and visual thinking // European journal of natural history. 2010. № 2. P. 38-42.

11. Zhukovskiy V.I., Pivovarov V. D. Characteristics of visual thinking The // European journal of natural history. 2009. № 6. P. 38-44. 